\title{
ANALYSIS OF COLLIDING VEHICLE INTERACTIONS FOR THE PASSENGER RAIL TRAIN-TO-TRAIN IMPACT TEST
}

\author{
Richard Stringfellow \\ Robert Rancatore \\ Patricia Llana \\ TIAX LLC \\ Cambridge, MA \\ Ronald Mayville \\ R.A. Mayville \& Associates \\ Newton, MA
}

\section{ABSTRACT}

A full-scale train-to-train impact test was performed in which a cab car-led passenger train traveling at $30 \mathrm{mph}$ collided with a standing locomotive-led train. During the test, the lead cab car overrode the cab of the standing locomotive, sustaining approximately 20 feet of crush, while the cab of the locomotive remained essentially intact.

In this study, a finite element-based analysis of the collision was performed. The first 0.5 seconds of the collision was simulated. Results of the analysis were compared with accelerometer and video test data. Specific comparisons are made between test data and model predictions for: motions of the cab car and the standing locomotive; longitudinal forces arising between the cab car and the standing locomotive and between the respective lead and trailing vehicles; and the mode of deformation of the cab car and the locomotive.

The results of the study indicate that the model captures pertinent features of the first 0.3 seconds of the collision, particularly with respect to longitudinal vehicle motions and collision forces. After 0.3 seconds, agreement between model predictions and test data becomes progressively worse. This is attributable to the model's inability to capture the massive fracture that occurs at the front of the cab car.

\section{INTRODUCTION}

The Volpe National Transportation Systems Center is conducting ongoing research into the crashworthiness of rail vehicles in support of the Federal Rail Administration's Office of Research and Development. Two integral components of this research include the development of computer models for simulating rail vehicle collisions, and full-scale collision testing of rail equipment.

These two aspects of rail crashworthiness research go hand-in-hand. Computer models allow for study of the response of rail equipment over a wide range of collision scenarios and for assessment of the effects of vehicle modifications in a cost- effective manner. Full-scale testing provides (among other goals) a means to validate these models so that they can be applied over the desired range of collision conditions.

As part of a series of full-scale tests, a train-to-train impact test was performed on January 31, 2002 at the Transportation Technology Center in Pueblo, Colorado. In this test, a cab carled passenger train, consisting of a cab car, three coach cars and a trailing locomotive, traveling at $30 \mathrm{mph}$, collided with a standing locomotive-led train with two ballasted hopper cars. Each train had a total weight of about $635,000 \mathrm{lbs}$. In the test, the lead cab car overrode the cab of the standing locomotive, sustaining approximately 20 feet of crush (see Figures 1 and 2), while the cab of the locomotive remained essentially intact, with the anticlimber skirt and short hood denting-in and the windshield center post crushing by about one foot.

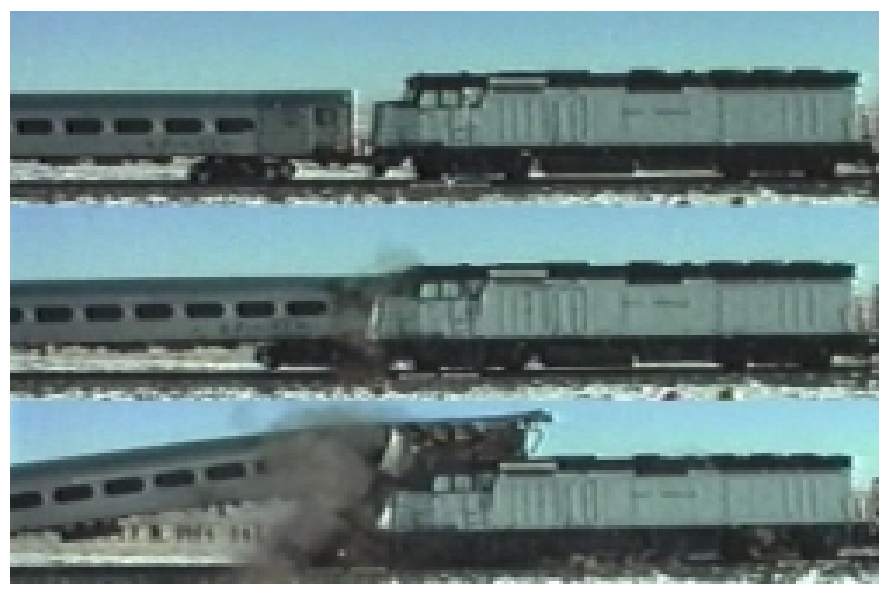

Figure 1. Images taken from high-speed film showing the cab car catapulting over the standing locomotive [1]. 


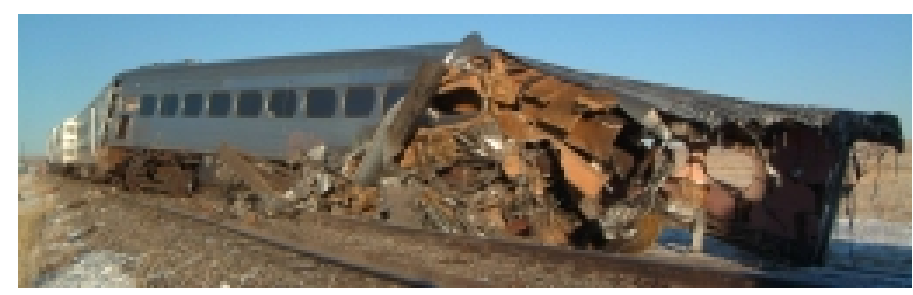

Figure 2. A photograph of the cab car-led train, following the collision [1].

In this study, we simulated this collision using explicit/dynamic finite element analysis (ABAQUS/Explicit). In comparison to other vehicle collision studies that we and others have performed [2-7], this study is the first in which the interactions of colliding vehicles have been modeled using detailed FEA.

Simulation of the test provides several benefits. It increases our capability for vehicle crush modeling to include vehicle-to-vehicle interactions. It also provides a platform for studying the effect of trailing vehicles on lead vehicle crush behavior. Finally, it provides insight into the modes of deformation and crush forces that were observed in the test.

Previous analyses of train collisions have typically broken the problem into three parts: the crush behavior of the cars, the overall dynamics of the train, and the dynamics of the occupant inside the train. The crush behavior of the cars is evaluated with non-linear FEA to determine the force required to crush the car and the shape of the car as it crushes. The collision dynamics behavior is evaluated with lumped-parameter model to determine the distribution of crush among the cars, and the trajectories of the cars during a collision, including the deceleration of the cars. The occupant dynamics is evaluated with a lumped-parameter model to determine the forces and decelerations of the occupants. Comparisons with the results of full-scale testing have shown this approach to be effective in predicting impact test results [3-7].

Analysis of the train collision dynamics with a lumpedparameter model requires heuristic elements to approximate the interaction of the colliding equipment. Development of these elements relies on the interpretation of the crush analyses of the equipment, and may draw on prior knowledge of the modeler about the interaction of similar equipment under similar impact conditions.

The approach used in this effort was to integrate the crush analysis of the individual cars with the collision dynamics analysis of the entire train. By using FEA for both components of the analysis simultaneously, the interaction of the impacting equipment is more explicitly represented than it would be using separate models. The principal potential advantage of this approach lies in its ability to directly evaluate the influence of changes in the structural design of the vehicles, including geometry and materials, on the outcome of the collision. This approach therefore lends itself to refining a rail car's structural design more efficiently that it can be refined using typical analysis methods.

One note of caution: although this approach allows for a more direct representation of the interaction of the impacting bodies, it does have potential pitfalls, including the modeling of material failure. The representation of material failure is quite simple in nonlinear FEA codes in comparison to the actual phenomenon. One must therefore be careful when selecting material failure parameters.

\section{OBJECTIVES AND APPROACH}

In order to provide specific bases against which to compare the results of our model, we first identified, collected and organized appropriate subsets of the data that had been measured during the collision and processed by the Volpe Center.

The test vehicles were each instrumented with a number of accelerometers, string pots and strain gages. In addition, highspeed film was taken of the collision from several perspectives. Our approach included review of the high-speed film, development of Excel-based data and graphics files for direct comparisons to model results, and review of selected data sets to ensure that appropriate comparisons were selected.

We next developed the finite element model of the two trains. We started with models that had been previously developed in prior programs for crush analysis of each of the two lead vehicles - the cab car and the standing locomotive. We made a significant number of modifications to each of these models and developed new sub-models defining truck-to-body connections for the cab car and defining the behavior of the colliding couplers. We used lumped mass elements to model trailing vehicles.

We then exercised the model and compared the results to the test data that we had previously identified. This was an iterative process that resulted in a number of modifications to the model.

Our primary goal was to simulate, with sufficient accuracy, the first 0.25 seconds of the collision, which produced nearly 8 feet of crush between the colliding vehicles.

\section{MODEL DEVELOPMENT}

The finite element model is made-up of four key elements: (1) the cab car body; (2) cab car trucks and truck-to-body connections; (3) the standing locomotive; and (4) trailing vehicles and vehicle-to-vehicle connections.

\section{Cab Car Body}

The model for the cab car body was, in part, derived from models that had been developed in prior investigations. As a starting point, we used a model that was specifically used for analysis of a representative 1990's car body [3,6]. This model featured a detailed discretization of the front 20 feet or so of the cab car, using a characteristic element length of approximately 1.5 inches. We then added to it a model for the rear-most 60 feet or so of the vehicle. In order to minimize the number of elements, this part of the vehicle was modeled in much less detail, with a characteristic element length of approximately 15 inches. A mesh transition zone about 4 feet in length was developed to link the refined and coarse parts of the mesh. The mesh for the cab car is shown in Figure 3. The mesh consists of approximately 125,000 shell elements, with 118,000 of these representing the more refined forward end of the cab. 

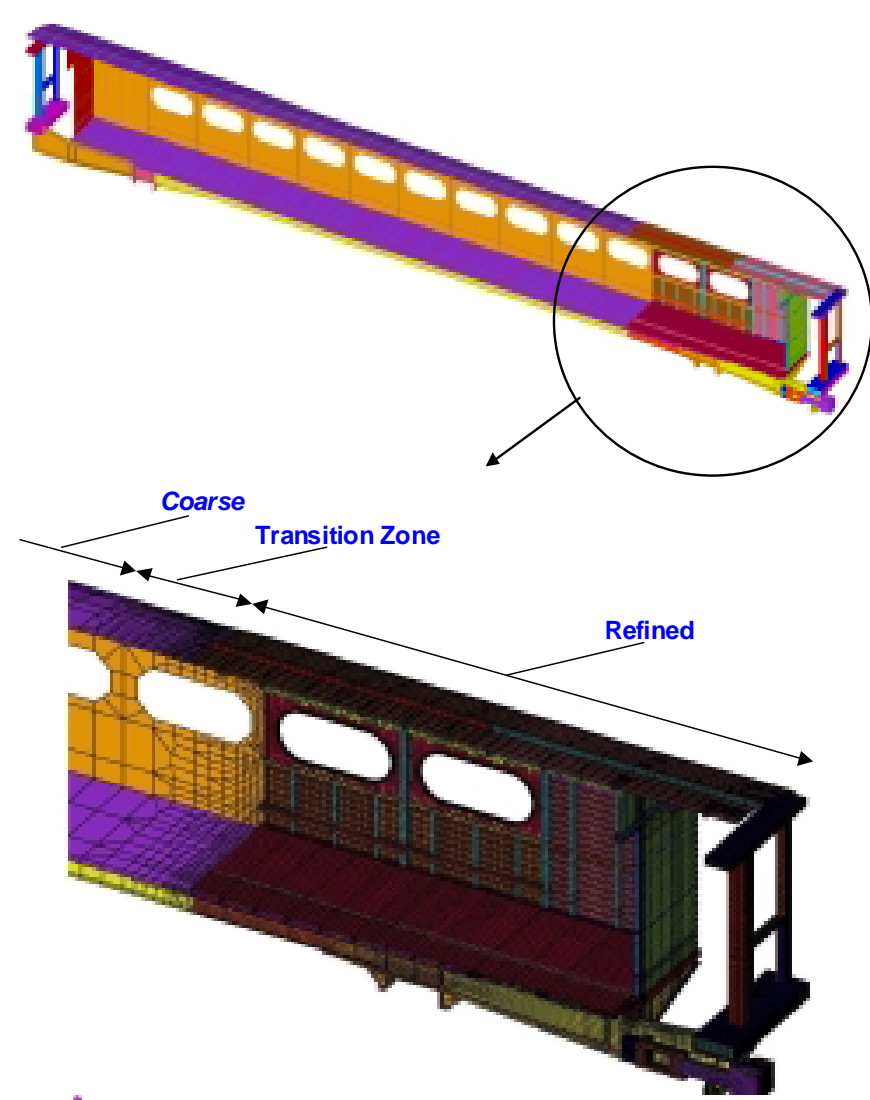

Figure 3. The finite element model of the cab car.

\section{Locomotive}

In a like manner, the mesh for the locomotive was derived from models used in previous programs. In this case, we started from a model of the cab of an EMD locomotive [7]. We then added detailed representations for the short hood, collision posts, anticlimber, draft pocket, and draft gear. In addition, we added simplified representations for the underframe, engine, trucks and fuel tank. Because the damage to the locomotive was limited to the very front of the vehicle, most of the vehicle was modeled as a rigid body. This allows us to represent this part of the mesh with a single node, having the correct mass and inertia properties, and with the ability to translate in 3 directions and rotate about 3 axes. This greatly decreases the solution time for the model. Figure 4 shows the model for the locomotive. The mesh consists of about 16,000 elements, of which about 7,000 are deformable elements.

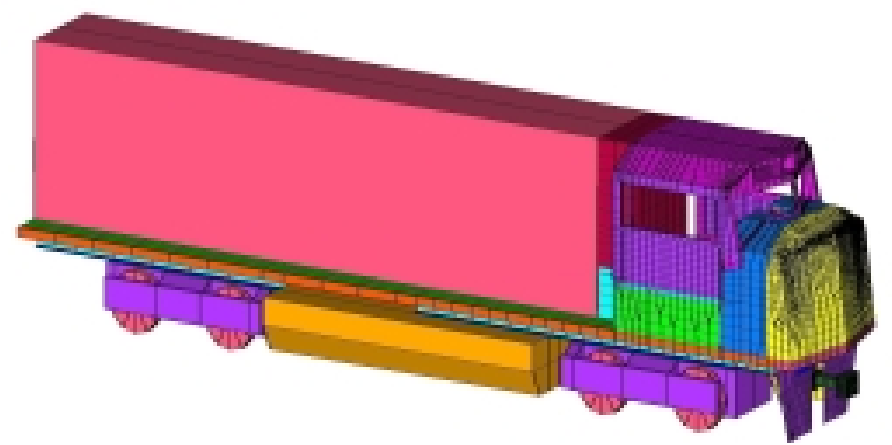

Figure 4. The finite element model of the standing locomotive.

\section{Trucks and Truck-to-Body Connectors}

The cab car trucks were modeled as rigid bodies connected to the underframe of the cab car body through the use of ABAQUS connector elements. The structure of the truck was derived from a model developed for a previous study [6]. The stiff longitudinal connection of the truck to the body bolster was modeled as acting through the center pin using a 'SLIDE PLANE' connector element. The much more compliant vertical and lateral connections to the body bolster acting through the diaphragms were modeled using 'RADIAL THRUST' connector elements. In addition, connectors simulating contact between the wheel and the rail were applied between the center of each of the four wheels and a rigid plane representing the rail/ground using a 'CARTESIAN' connector. This connector type provides for the definition of limits to relative motion between two model components in a specified direction. Finally, connector elements are included for a set of hooks that connect the truck to the bolster and prevent additional extension of the secondary suspension after the maximum travel of 2 inches has been reached. Figure 5 shows the truck and truck connectors. The mesh for each truck consists of approximately 13,000 elements, all rigid. Again, it is worth noting that the presence of rigid elements does not significantly affect solution time.

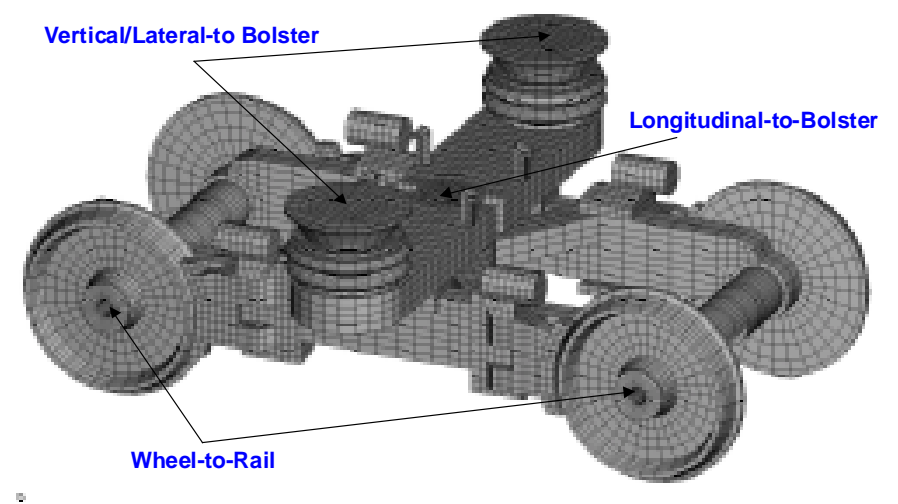

Figure 5. The finite element model of the truck/truck connectors.

\section{Trailing Vehicles and Vehicle Connections}

Trailing vehicles (three coach cars plus a trailing locomotive for the moving consist; two ballasted hopper cars for the standing consist) were modeled in a simplified manner using lumped masses, located at the vehicle c.g.'s and matched to the measured weight of the vehicle. Vehicle connections were represented with nonlinear spring and linear dashpot elements acting in parallel. The force-deflection characteristics of the nonlinear spring elements represent, in series, the compliant behavior of the coupled draft gears and the much stiffer behavior of the vehicle underframes. Dashpot characteristics represent the damping of the vehicles and their connections, which occurs mostly through hysteresis of the draft gear pads. These elements were constrained to move only in the longitudinal direction. Specific values used in the model were chosen to be consistent to collision dynamics models that were developed by the Volpe Center $[1,8]$. 
The entire model is depicted in Figure 6. Note that the truckto-vehicle connector elements, which do not lend themselves to visualization, are not depicted.

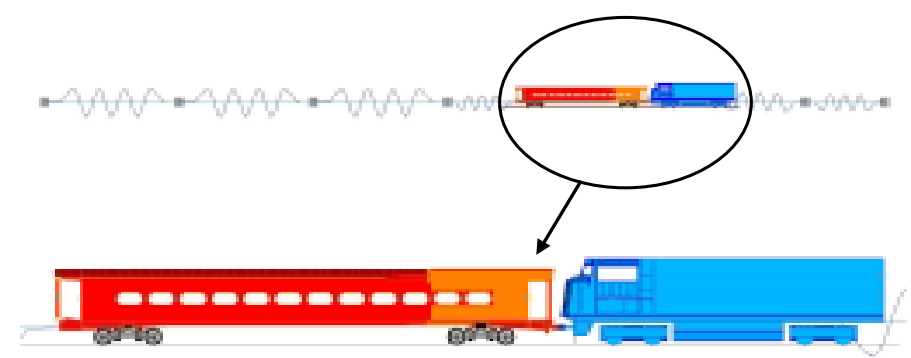

Figure 6. The complete finite element model.

A key feature of the modeling approach was the use of automatic contact, a relatively new feature of ABAQUS/Explicit. The implementation of this feature made it much easier to model the complex contact interactions between the various deforming structure of the cab car. Its use did, however, require a significant number of modifications to the models, which had not originally been set-up to run with the automatic contact feature.

The model also includes limited use of one of the material failure features of ABAQUS/Explicit. Failure was restricted to the draft sill structures, using a strain-based material law with a failure strain of 30 percent. Our experience in this program and others suggests that the use of the material failure options in conjunction with contact can often lead to numerical difficulties that prevent the completion of the analysis. For this reason, a more aggressive approach to modeling failure was not used. As is discussed in the next section, this leads to deviations between the predictions of the model and the test results once massive fracture begins to drive the collision behavior. We found that this issue arises after about 0.3 seconds.

\section{COMPARISON OF MODEL AND TEST RESULTS}

Comparisons between the model and the test were made in terms of four different measures of collision behavior:

- Deformation modes - the deformed shape of the forward end of the cab car and, to a lesser extent, the forward end of the standing locomotive, as a function of time during the collision.

- Colliding vehicle motions - longitudinal, vertical and lateral displacements, velocities and accelerations of the cab car and the standing locomotive;

- Collision force - longitudinal force between the cab car and the standing locomotive;

- Forces imparted by trailing equipment - longitudinal forces acting between the cab car and the $1^{\text {st }}$ coach car and between the standing locomotive and the $1^{\text {st }}$ ballasted hopper car;

\section{Deformation Modes}

Deformation modes of the colliding vehicles were captured both by means of analysis of video stills taken from high-speed film and through inspection of the deformed structures following the collision. Each of these provides limited information. The high-speed film shows only the side exterior of the cars, and post-mortem examination only reveals the final state of individual component deformation. Nevertheless, much can be deduced from these two sources. follows:

The sequence of deformation appears to have proceeded as

1. The couplers of the impacting vehicles struck in line, forcing the weaker cab car coupler back into its pocket. This coupler displacement likely resulted in deformation of the draft sill as well as severe deformation and fracture of the draft gear pocket. Such deformation has been observed in previous full-scale tests on similar cars [9, 10].

2. The cab car coupler was pushed back enough, perhaps with a bit of sideways motion of the locomotive coupler, to permit the anticlimber of the locomotive to strike the collision posts of the cab car. Post-test examination shows that a severe impact occurred only on one of the cab car collision posts and the corresponding side of the locomotive (see Figures 7 and 8a). This suggests that deformation and fracture from push back of the coupler may have weakened the opposite side.

3. At the same time the draft sill deformed, permitting the bottom of the cab car end frame to be displaced inward with respect to the top, taking the shape of the front of the locomotive short hood. This deformation is very evident from a series of video images captured from the high-speed film (see Figure 9). Post-test examination indicates that the draft sill deformation was at least partly accommodated by forming a Z-shape in an approximate horizontal plane.

4. There was also a twisting deformation - about $15^{\circ}-$ of the end frame about the car longitudinal axis as evident from the imprint it made on the locomotive hood (Figure 8a).

5. It appears that the end frame was eventually pushed inward more on one side than the other which then eventually caused the car to be pushed to one side off the track.

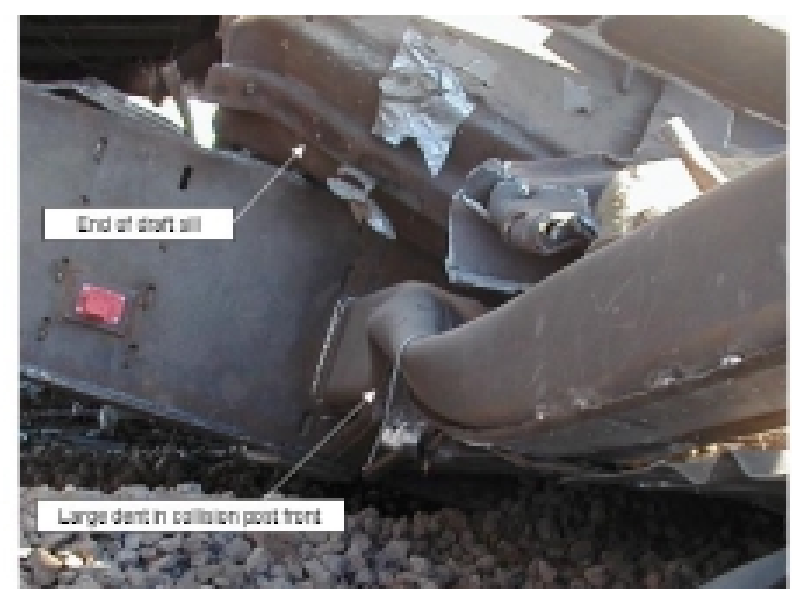

Figure 7. A post-test photograph of the cab car end frame and draft sill end. 


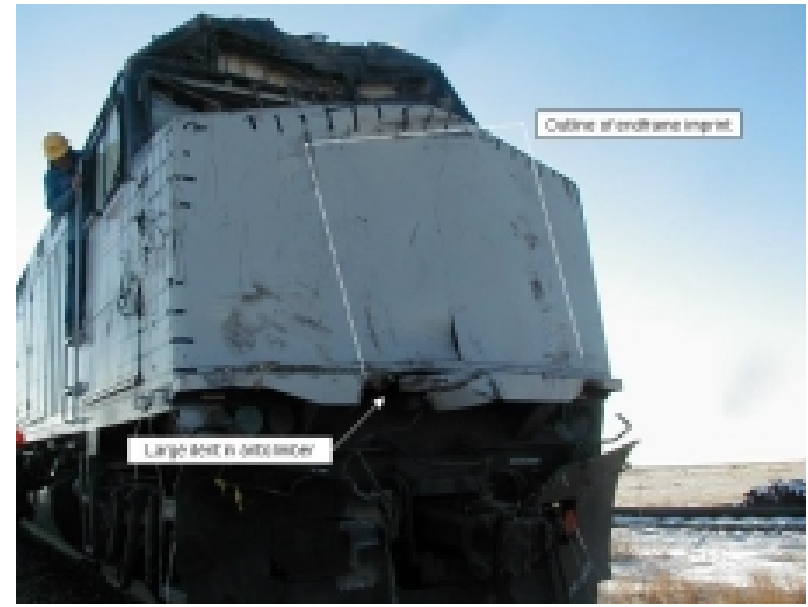

(a)

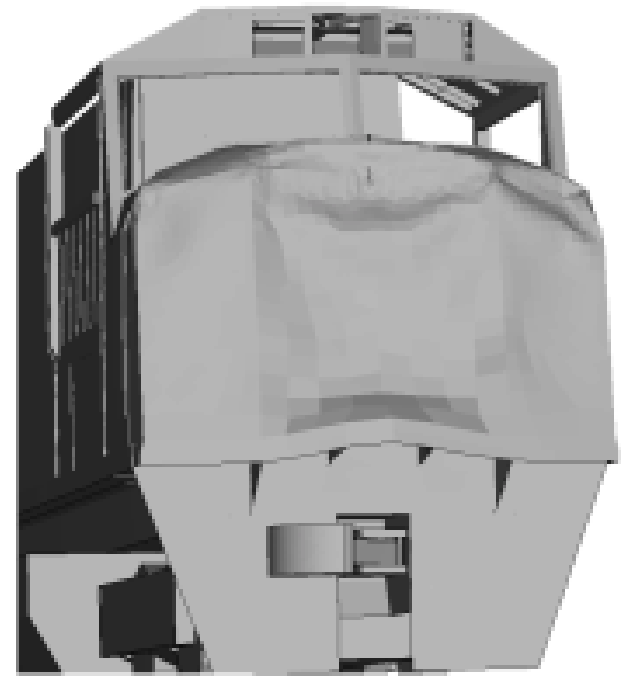

(b)

Figure 8. (a) A post-test photograph of the front of the standing locomotive showing the imprint of the cab car end frame; (b) The model-predicted damage to the front of the locomotive.

For comparison, Figure $8 \mathrm{~b}$ shows the predicted deformed locomotive end after 0.5 seconds. The predicted damage to the upper front face of the short hood is very consistent with the test, as is the sideways motion of the coupler. Interestingly, the coupler moves in a direction that is opposite to the direction that it moved in the test. This is likely the result of an initial condition that was imposed on the model couplers. They were offset in angle by approximately five degrees in order to provide some asymmetry to the model and mimic naturally occurring misalignments. As the remainder of the model is symmetric, offsetting the couplers in the opposite direction would have captured the actual motion of the coupler.
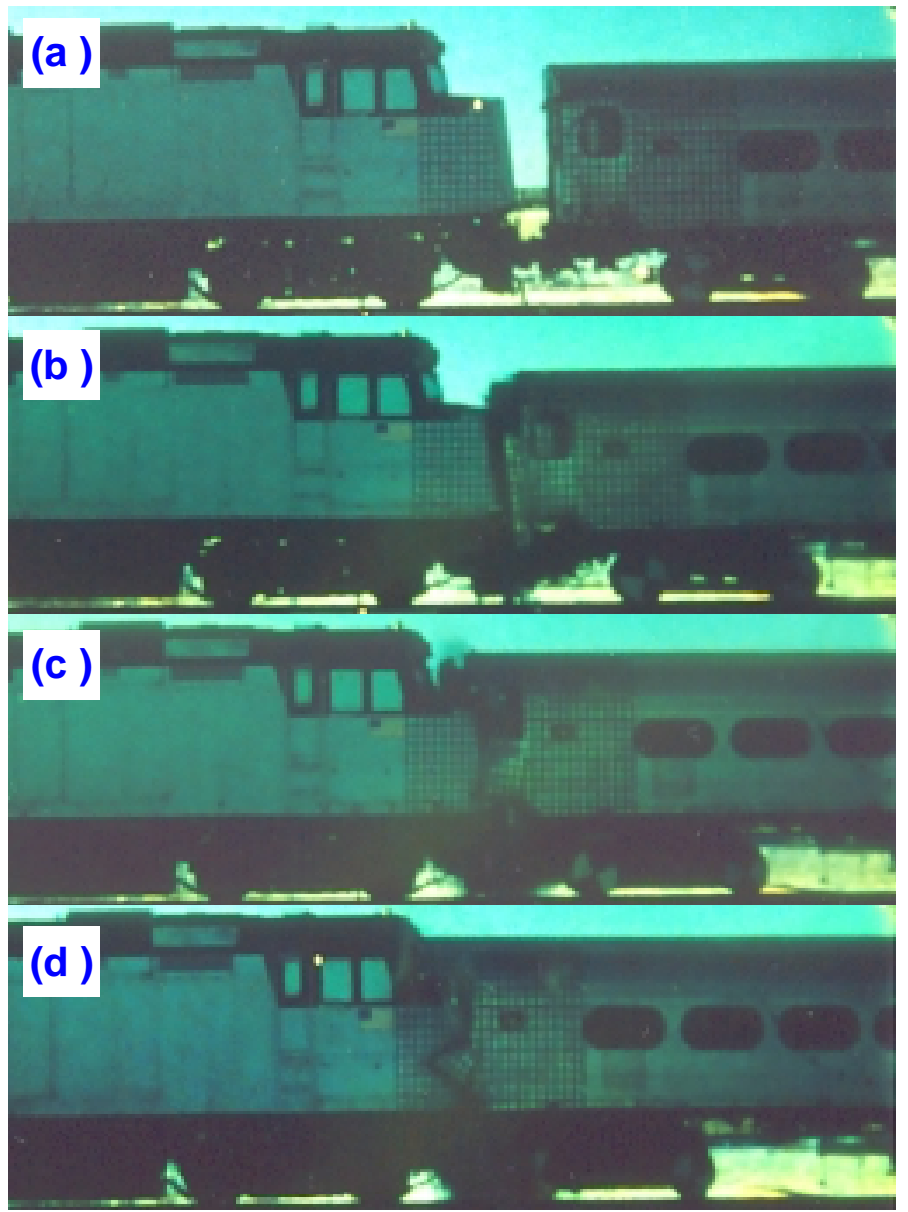

Figure 9. Video stills taken from high-speed film at (a) impact; (b) after 0.077 seconds; (c) after 0.157 seconds; and (d) after 0.250 seconds.

Figure 10 shows side views of the collision taken from the model results at impact and after approximately 0.084 seconds, 0.156 seconds, and 0.252 seconds. In comparison with the video images shown in Figure 9, the model appears to capture the downward bending of the end frame of the cab car onto the front of the short hood, the downward bending of the front of the draft sill, and the subsequent impact of the cab car roof structure against the window frame of the locomotive cab. The mode of deformation for the draft gear appears to differ somewhat from that of the test. In the test, the draft gear appears to bend downward from a single plastic hinge point near the forward truck wheel. In the model, there are two plastic hinge points above the forward wheel, so that the middle of the draft gear actually bends upward. These differences could easily be attributable to small differences between the characteristics of the model draft sill and the actual draft sill. This is particularly true when one considers the large extent of fracture that occurred in the draft sill.

Another notable difference between the model and the test is in the lifting of the forward truck wheels. For the model, at 0.252 seconds (Figure 10d), the wheels have lifted several inches. In comparison, in the test at 0.250 seconds (Figure 9d) the wheels appear to be just starting to lift. Note that, in the 
test, as is evident in Figure 1, the wheels of the truck did begin to lift noticeably shortly thereafter.
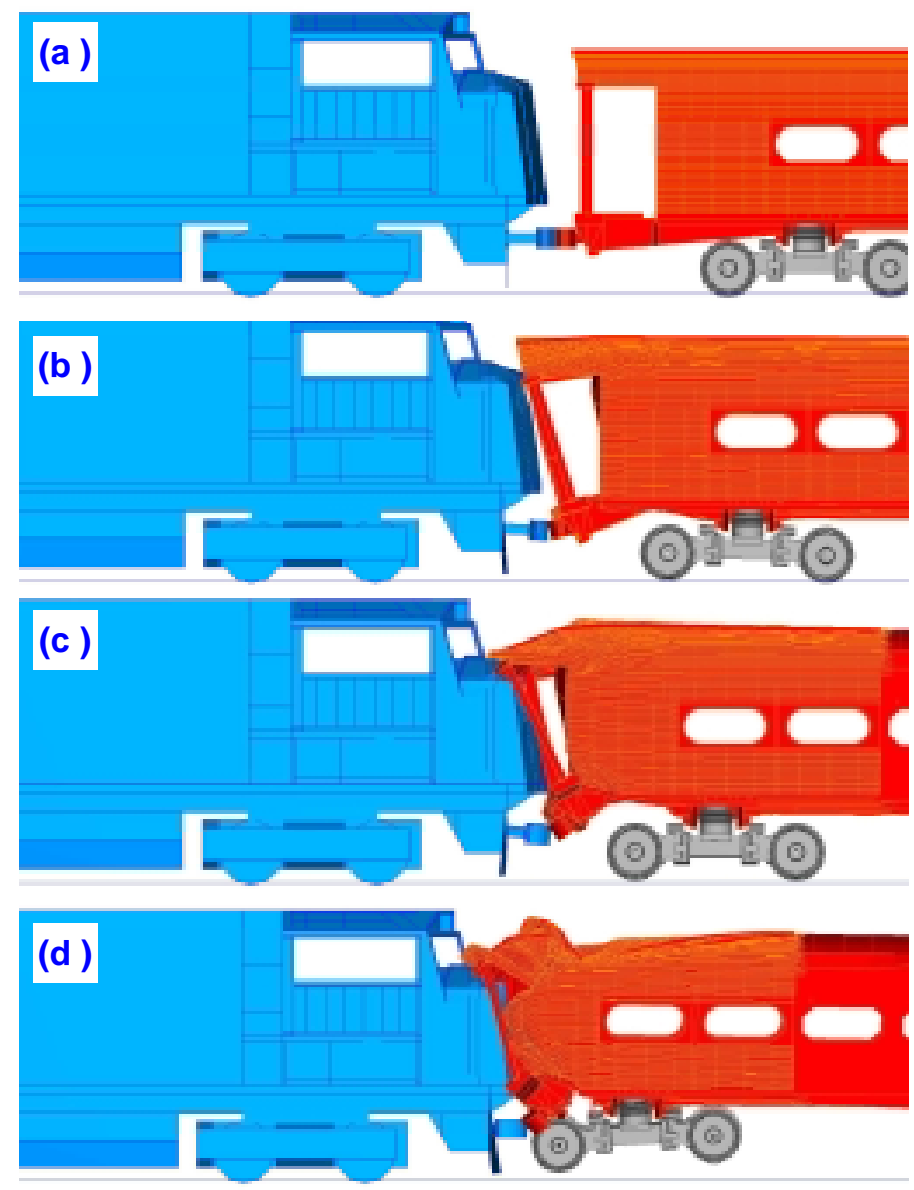

Figure 10. Side view of the collision taken from the model results: (a) impact; (b) after 0.084 seconds; (c) after 0.156 seconds; and (d) after 0.252 seconds.

\section{Colliding Vehicle Motions}

In the test, vehicle motion data was derived from two sources: accelerometers and high-speed film. Each vehicle was outfitted with a number of accelerometers, allowing for determination of vehicle motions in all three directions. The raw acceleration data were processed by the Volpe Center according to SAE J211 standards. Vehicle acceleration time histories were generated using a CFC 60 (Butterworth 4-pole phaseless digital) filter. Velocity time histories were generated using a CFC 180 filter on the acceleration data and then numerically integrating using the trapezoidal rule. Displacement time histories were similarly generated by filtering at CFC 180 and double-integrating. Displacement data were also generated through photometric analysis of high-speed film. In order to produce meaningful comparisons, model predictions of acceleration were also filtered using SAE J211/CFC 60. A comparison of the filtered longitudinal deceleration time histories for the cab car is shown in Figure 11.

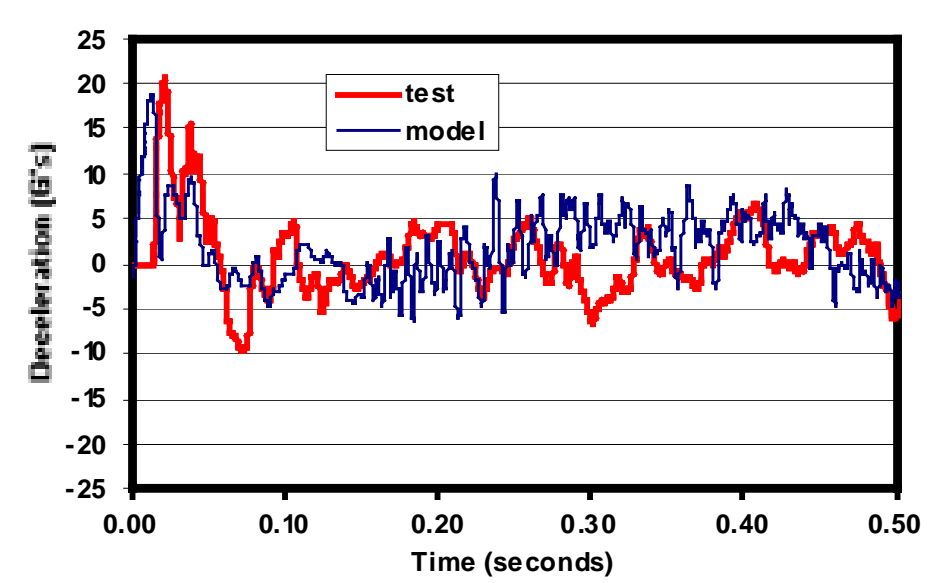

Figure 11. Comparison of model and test: cab car longitudinal deceleration.

The model captures the peak deceleration of about $20 \mathrm{G}$ 's quite well, though the timing appears to be off by about 0.01 seconds. This may simply be due to a shift in the time of impact recorded in the test. The model generally follows the trend of the data over this 0.5 -second interval. It does not capture the full-extent of the $10 \mathrm{G}$ negative deceleration (positive acceleration) that occurs at 0.07 seconds. This may be attributable to the simplified manner in which the damping characteristics of the trailing vehicle connections are modeled - earlier versions of the model that did not include damping captured this pulse more accurately. The higher modelpredicted decelerations that occur after 0.3 are likely due to the aforementioned less aggressive approach to modeling fracture.

In comparison to accelerations, displacement trends are less difficult to track. Figure 12 shows a comparison of cab car, locomotive, and crush (cab car minus locomotive) displacements versus time. As is evident in this figure, the model and test results compare quite favorably over the first 0.25 seconds or so. After this time, the respective curves tend to deviate from one another, as the model loses accuracy. This appears to be due to the significant extent of fracture that arises, which the model does not accurately capture. The extensive fracture lowers the resistance of the cab car structure, and therefore promotes additional displacement with time. 


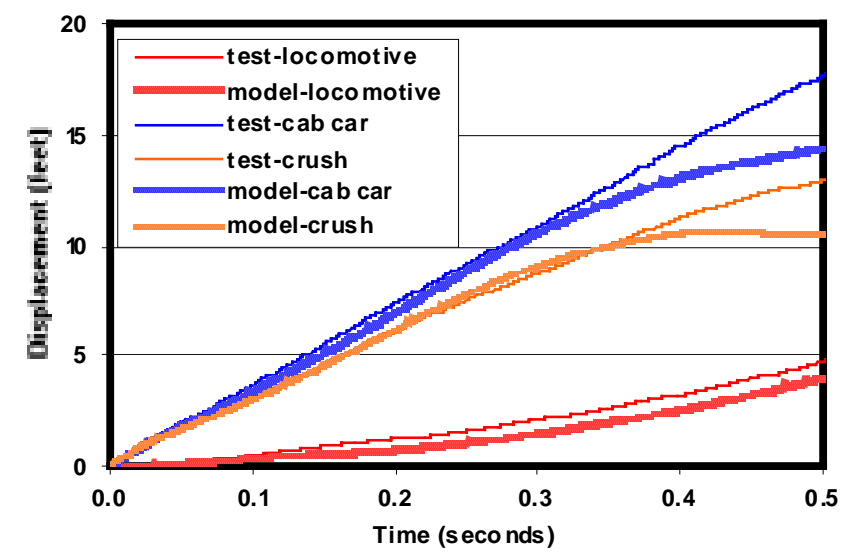

Figure 12. Comparison of Model and Test: Cab Car, Locomotive and Crush Displacements.

As is evident in Figure 1, the forward end of the cab car lifted up and eventually catapulted over the cab of the standing locomotive. One of the goals of this program was to provide the model with the ability to capture this aspect of the collision. Figure 13 shows a comparison of the cab car pitch versus time. Based on the agreement between model and test results, it appears that the model captures the initiation of lift well. For the model, after about 0.3 seconds, further lift of the vehicle is resisted because, without extensive fracture, the endframe becomes trapped by the locomotive anticlimber and short hood.

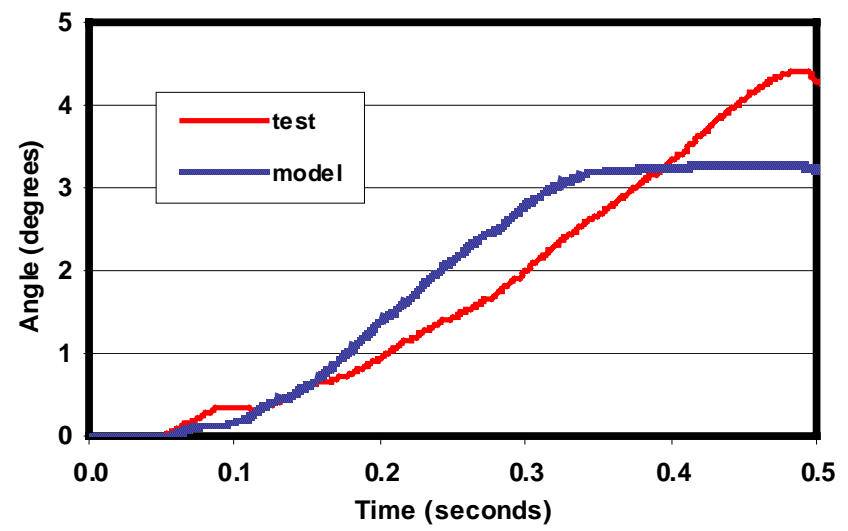

Figure 13. Comparison of Model and Test: Cab Car Pitch.

\section{Collision Forces}

The collision force-time history was derived from the acceleration- time histories under the assumption that each consist behaves as a lumped-mass system. This assumption leads to two estimates of the collision force that are based on: in one case the sum of the masses of the individual vehicles from the moving consist multiplied by their respective masses; or in the other case, the sum of the masses of the individual vehicles from the standing consist multiplied by their respective masses. Unfortunately, the acceleration measurements for the standing locomotive appear to have been corrupted due to loose engine mounts [8]. Therefore, for the test, the calculation of force based on the standing consist is not considered to be reliable, and it is therefore not used for comparison with model results.
A comparison of the collision force based upon test and model-predicted accelerations is shown in Figure 14. Note that, for the model, force estimates can be derived from accelerations of both the moving and standing consists. As the plot indicates, there appears to be better agreement between the model and the test when the model's standing consist acceleration data is used. The calculation based on the moving consist vehicles is greatly influenced by the accelerations of the trailing vehicles, which were modeled in a very simple manner. This is discussed more in the section on trailing vehicle forces, below.

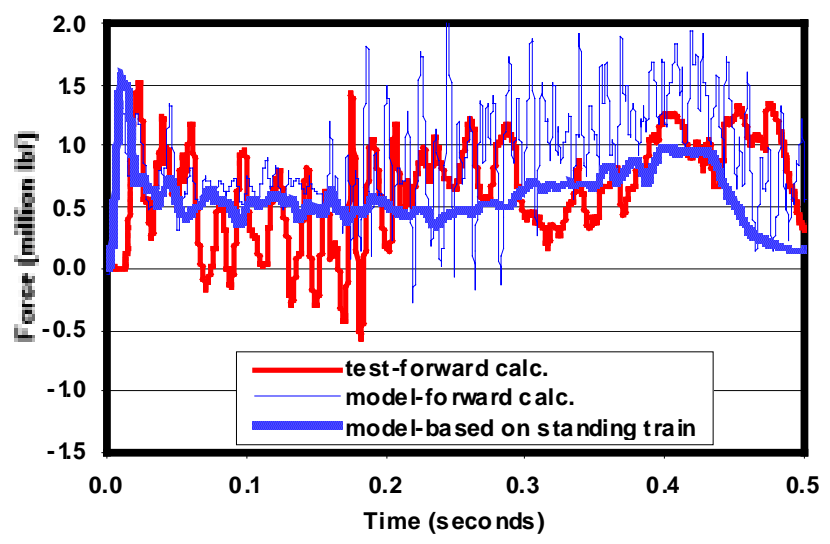

Figure 14. Comparison of Model and Test: Collision Force.

\section{Trailing Vehicle Forces}

The forces imparted by trailing vehicles were calculated in a manner that is similar to that used to calculate the collision force. In this case the force on the lead vehicle is simply equal to the sum of the masses times the accelerations of each of the trailing vehicles.

Figures $15 \mathrm{a}$ and $15 \mathrm{~b}$ compare the trailing vehicle force histories for moving and standing consists, respectively. Note in Figure 15a the delay in the initial peak force relative to the time that it occurred at the collision point. Of particular interest for this study is the large magnitude of the trailing force acting on the cab car. In comparison to a single-vehicle collision the trailing force clearly has a significant effect on the collision force. It is clear from Figure 10a that the simplified manner in which the trailing vehicles were modeled does not allow for accurately capturing the oscillations in the curve that are indicated in the test data. However, it also appears that the magnitude of the forces over the first 0.25 seconds is higher on average than the test data. This indicates that the values used for the stiffness and damping characteristics may need to be modified. On the other hand, the trailing force on the locomotive seems to be captured well by the simplified model of its trailing vehicles. 

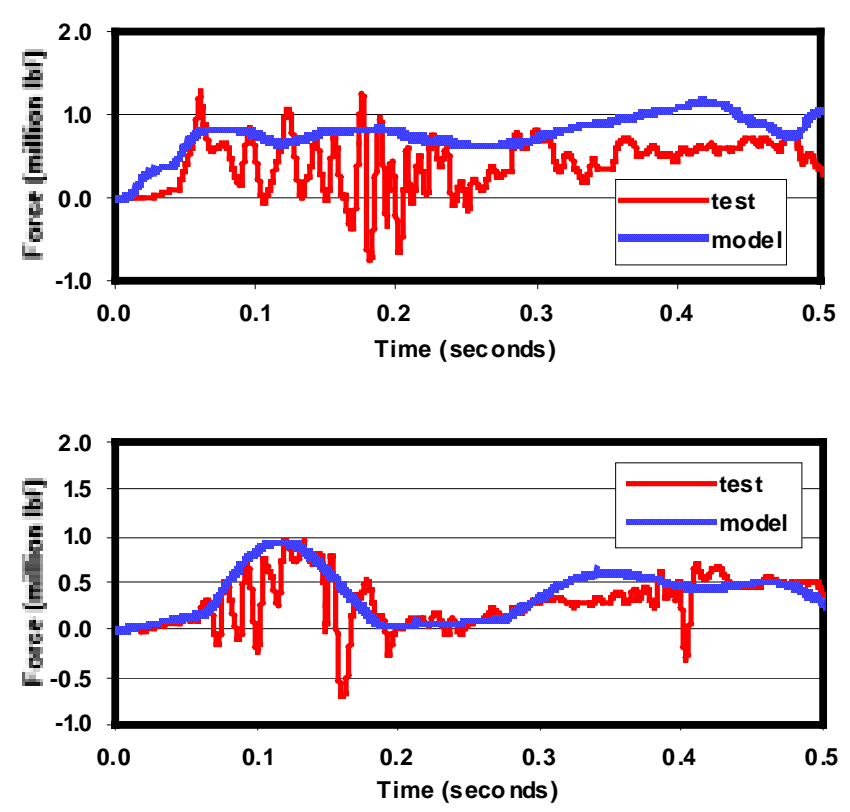

Figure 15. Comparison of Test and Model: Trailing Force at Rear of (a) Cab Car and (b) Rear of Standing Locomotive.

\section{SUMMARY AND CONCLUSIONS}

In summary, it appears that the detailed finite element simulation of the collision of this train-to-train test captures many aspects of the collision behavior. In particular, the everimportant longitudinal motions and collision forces were predicted with a fair degree of accuracy, especially at the early stages of the collision.

Based upon the results of this study, it is evident that there are two aspects of the collision that need to be better understood: the effect of trailing vehicle mass and vehicle-tovehicle connection parameters on the trailing vehicle force, and the role of fracture on the deformation of the end frame. The issue of fracture is most critical if one wishes to accurately simulate later stages of collisions like the one that occurred in the full-scale test, where fracture becomes the dominant deformation mechanism. Based on our experience, additional model development is required to accurately model the complex interplay between the fracture of and the contact interactions between key structures.

\section{REFERENCES}

1. Tyrell, D., Severson, K., Perlman, A.B., Rancatore, R., "Train-to-Train Impact Tests: Analysis of Structural Measurements," Proceedings of IMECE'02, the 2002 ASME International Mechanical Engineering Congress and Exposition, November 17-22, New Orleans, Louisiana.

2. Stringfellow, R., Mayville, R., Rancatore, R.," Evaluation of Protection Strategies for Cab Car Crashworthiness," Arthur D. Little, Inc. Report Reference 30299-05 (January 2000).
3. Mayville, R.A., Johnson, K., Stringfellow, R.G., "Development of Conventional Passenger Cab Car End Structure Designs for Full-Scale Testing," TIAX Final Report to the Volpe National Transportation Systems Center, Cambridge, MA, Reference 74431 (December 2002).

4. Martinez, E., Tyrell, D. and Zolock, J., "Rail-Car Impact Tests with Steel Coil: Car Crush," in Proceedings of ASME/IEEE Joint Railroad Conference, April 22-24, 2003, Chicago, IL.

5. Tyrell, D.C., Severson, K.J., Mayville, R.A., Stringfellow, R.G., Berry, S. and Perlman, A.B., "Evaluation of Cab Car Crashworthiness Design Modifications," in Proceedings of the 1997 IEEE/ASME Joint Railroad Conference, March 18-20, 1997, Boston, MA, pp. 49-58.

6. Kirkpatrick, S., MacNeil, R., "Development of a Computer Model for Prediction of Collision Response of a Railroad Passenger Car," Proceedings of the 2002 ASME/IEEE Joint Railroad Conference, April 23-25, 2002, Washington, D.C.

7. Tyrell, D., Severson, K., Marquis B., Martinez, E., Mayville, R., Stringfellow, R., Hammond, R., Perlman, A.B., 1999, "Locomotive Crashworthiness Design Modifications Study, “ Proceedings of the 1999 IEEE/ASME Joint Railroad Conference, April 13-15, 1999, IEEE Catalog Number 99CH36340, ASME RTD Volume 16.

8. Tyrell, D., "Passenger Rail Train-to-Train Impact Test Volume I: Overview and Selected Results," U.S. Department of Transportation, DOT/FRA/ORD-03/17.I, July 2003.

9. Tyrell, D., Severson, K., Perlman, A.B., "Single Passenger Rail Car Impact Test Volume I: Overview and Selected Results," U.S. Department of Transportation, DOT/FRA/ORD-00/02, March 2000.

10. Tyrell, D., Severson, K., Perlman, A.B., "Passenger Rail Two-Car Impact Test Volume I: Overview and Selected Results," U.S. Department of Transportation, DOT/FRA/ORD-01/22.I, January 2002.

\section{ACKNOWLEDGEMENTS}

This work was performed under contract for the Volpe Center as part of the Equipment Safety Research Program sponsored by the Office of Research and Development of the Federal Railroad Administration. This contract was initiated and monitored by David Tyrell, Senior Engineer, and Volpe Center. The authors would like to thank Dr. Tom Tsai, Program Manager, and Claire Orth, Division Chief, Equipment and Operating Practices Research Division, Office of Research and Development, Federal Railroad Administration, for their support. The authors would also like to thank Eloy Martinez, Kari Jacobsen and John Zolock of the Volpe Center and Benjamin Perlman of Tufts University for their helpful review and suggestions. 